\title{
Estratégias Dialógicas de Auto-Organização da Identidade: Psicoterapia e Reestruturação da Gestão Interna ${ }^{1}$
}

\author{
Catarina Rosa ${ }^{2}$ \\ Universidade de Aveiro \\ Miguel M. Gonçalves \\ Universidade do Minho
}

\begin{abstract}
RESUMO - A identidade tem sido um conceito central na literatura em psicologia e na forma como as diferentes abordagens terapêuticas têm concebido os processos de mudança. Entre as inúmeras perspectivas desenvolvidas sobre essa dimensão do ser humano, destacamos o paradigma dialógico que tem vindo a influenciar de forma crescente a teoria e prática em psicoterapia. Segundo esta perspectiva, a funcionalidade psicológica está relacionada com o modo como os indivíduos conseguem articular e colocar em diálogo produtivo as suas várias vozes ou posições de identidade. Neste artigo apresentamos uma revisão da literatura sobre as estratégias que subjazem a essa capacidade auto-organizadora do sistema identitário e sobre as diretrizes que poderão orientar uma intervenção terapêutica dialógica quando essa capacidade se torna disfuncional.
\end{abstract}

Palavras-chave: identidade, perspectiva dialógica, dinâmica intrapessoal, sistema identitário, psicoterapia

\section{Dialogical Self Strategies of Self-Organization: Psychotherapy and Restructuring of Internal Management}

\begin{abstract}
Self-concept has been playing a crucial role in psychological literature and in the way the different therapeutic approaches conceive the processes of change. From the diverse perspectives developed about this human dimension, we emphasise the dialogical paradigm that has been increasingly influential in the psychotherapeutic theory and practice. According to the dialogical perspective the psychological well-being is dependent on the way individuals articulate and maintain productive dialogues between the different voices of the self or "I-Positions". In this paper we present a review of the literature on the strategies that underlie this self-regulatory ability of the self-system and the guidelines of the dialogical therapeutic intervention that could be used when these self-regulatory strategies become dysfunctional.
\end{abstract}

Key words: self, dialogical perspective, intrapersonal dynamics, self-system, psychotherapy

A identidade afigura-se como um conceito central para compreender a condição humana e o mundo envolvente e para explicar a forma como lidamos com o caos experiencial. Neste artigo tomamos o conceito de identidade como equivalente ao conceito anglo-saxónico de self. Assim, sempre que nos referimos a identidade estamos a considerar a identidade pessoal, isto é, o sentido que as pessoas fazem de si. Apesar de ser uma dimensão recorrente na teoria e na prática psicológica, a identidade não é um conceito fácil de definir e tem funcionado como uma fonte inesgotável de desenvolvimentos e publicações. As propostas recentes têm permitido reinventar perspectivas antigas e desenvolver novas visões. Um número crescente de teóricos e investigadores concorda que a identidade é um processo fluido e dinâmico, que é construído no tempo a partir de um sentido de autoria, que resulta do conjunto complexo de estados da mente que são organizados numa identidade narrativa (e.g. McAdams, 2001; Sarbin, 1986).

1 Apoio: Fundação para Ciência e a Tecnologia, Bolsa de Pós-Doutoramento com a referência SFRH/BPD/80671/2011

2 Endereço para correspondência: Universidade do Minho, Campus de Gualtar, Departamento de Psicologia Aplicada, Braga, Portugal, CEP 4710-057.E-mail. catarina.rosa@gmail.com
A perspectiva dialógica, enquanto teoria de compreensão e estudo da identidade, é herdeira dos modelos construtivistas nas ciências sociais e na psicologia. Deste modo, assume o carácter plural da identidade, em oposição à noção tradicional da identidade como entidade central unitária, e defende a co-existência de uma variedade descentralizada de posições do eu que elaboram diferentes significados pessoais sobre uma mesma experiência (Hermans \& Kempen, 1993).

No entanto, a perspetiva dialógica vai além da conceptualização múltipla da identidade e acrescenta-lhe o carácter multivocal, que se refere ao facto de cada posição poder ser dotada de uma voz que é capaz de comunicar os seus pontos de vista, desejos, motivos, sentimentos e memórias (Hermans, 1996). Podemos posicionar-nos em diferentes perspetivas do espaço identitário e, a partir daí, narrar diferentes histórias (Sarbin, 1993). Estas diferentes vozes, ou posições de identidade, relacionam-se através de interações, e tal como acontece com interações externas, podem desenvolver-se relações de acordo, desacordo, apoio, crítica, etc. (Hermans \& Hermans-Jansen, 2004). A integração e a coerência do sentido de identidade são obtidas, não através da presença de um narrador omnisciente (Hermans \& Kempen, 1993), mas através de um movimento dialógico entre as diferentes posições do eu (Lysaker, 2006). 
Essa perspetiva levanta inevitavelmente questões relacionadas com a necessidade de uma complexa e exigente capacidade de organização do sistema identitário. Como é regulada a fluidez de um sistema tão múltiplo e dinâmico, de forma a garantir a manutenção de um sentido de identidade? A crença numa função executiva auto-organizadora da própria identidade abre espaço à sua transformação voluntária e efetiva, seja na "vida comum", seja no contexto psicoterapêutico. Neste artigo analisamos um conjunto de contributos teóricos com o objetivo de aprofundar a nossa compreensão sobre as estratégias de auto-organização da multivocalidade, sobre o impacto desta capacidade auto-organizadora na funcionalidade psicológica e sobre a possibilidade de reorganização adaptativa do sistema identitário através da intervenção psicoterapêutica.

\section{A organização da identidade dialógica: estratégias de gestão da multivocalidade}

\author{
"Quem conhece os outros é sábio, \\ quem [se] conhece a si mesmo é iluminado." \\ (Confúcio)
}

Do ponto de vista dialógico, a identidade pode ser entendida como uma plataforma privilegiada de coabitação e comunicação entre as diferentes perspectivas que o indivíduo vai assumindo ao longo da sua experiência pessoal. No nosso entender, essa forma de pensar a identidade atribui-lhe um elevado grau de interessante dinamismo, mas ao mesmo tempo de perigosa instabilidade.

Somos constantemente confrontados com novas possibilidades que revelam as limitações da nossa visão presente e desafiam a nossa construção de identidade atual. Em resposta, e dada a possibilidade de comunicação e interação livre entre perspectivas diferenciadas, são ativados processos dialógicos de concordância, discordância, negociação, oposição, conflito, que exigem um esforço permanente de gestão adaptativa das dinâmicas envolvidas (Hermans, 2002, 2006). A sobrevivência e adaptação do sistema identitário ao longo do percurso de vida irão depender da capacidade de desenvolvimento e ativação de estratégias de gestão específicas, ou seja, da capacidade auto-organizadora da própria identidade.

Portanto, a questão que se impõe é a seguinte: como se processa esse plano interno de auto-organização? Propomos, neste artigo, que estes processos de auto-organização resultam da ação concertada de três elementos reguladores: um sistema hierárquico (gestão de poder através de relações de assimetria/simetria entre as posições); um sistema de prioridades (gestão de protagonismo pela diferenciação entre posições que ocupam o palco ou o background do sistema) e a ambivalência (gestão do nível de tensão que funciona como motor da troca intersubjetiva entre posições). Passaremos a descrever cada uma destas três estratégias a seguir.

\section{Sistema hierárquico}

A coexistência de perspectivas distintas, e que comunicam entre si, vai ativar inevitavelmente diferenças de poder.
Assim, no repertório de posições identitárias algumas vozes são mais importantes e influentes do que outras. As histórias contadas a partir da perspectiva de uma posição "superior" têm mais autoridade do que as histórias de outras posições. No entanto, o funcionamento desse sistema hierárquico só é adaptativo quando opera de forma fluente e bem distribuída. Ou seja, quando a interação entre as posições identitárias não é feita de forma aleatória, mas pelo contrário, é desenvolvida segundo o estabelecimento, e posterior dissolução, de hierarquias temporárias, periodicamente revistas ou atualizadas em resposta às situações de vida (Hermans, 1996; Lysaker, 2006; Valsiner, 2007).

Essa capacidade de organização eficaz pode falhar, dando lugar à inadequação e ao carácter estereotipado e rígido do sistema hierárquico (Guilfoyle, 2006). Num sistema hierárquico disfuncional, por exemplo, uma posição pode dominar invariável e tiranicamente sobre as restantes. Esse domínio injustificado empurra a identidade numa direção monológica e reduz a possibilidade de ocorrer um diálogo que permita a troca e modificação de perspectivas (Gonçalves, Matos, \& Santos, 2009; Hermans, 2004b; Hermans \& Hermans-Jansen, 2004; Salgado \& Gonçalves, 2007).

\section{Sistema de prioridades}

Para melhor clarificar o funcionamento deste sistema, recorremos à metáfora do teatro utilizada por Hermans (2006). As dinâmicas do repertório de posições de identidade podem ser comparadas a uma peça com diversos cenários. Em cada cenário, as motivações, os sentimentos, os aspectos culturais, os outros significativos, entre outros, irão determinar as posições que assumem o papel principal e ocupam o palco, ficando as restantes temporariamente no background.

Se todas as posições tivessem voz ativa sobre cada situação experiencial, o caos resultante impossibilitaria qualquer tomada de decisão e/ou ação (veja-se o conceito de cacofonia aplicado à esquizofrenia por Lysaker \& Lysaker, 2001, 2002, 2004). Para evitar o colapso da identidade, o sistema de prioridades opera através da distribuição alternada das posições de identidade entre as duas dimensões distintas do sistema (palco ou background), consoante a sua prioridade atual. As posições que são relevantes para um determinado momento "aqui e agora" ocupam o núcleo ativo, ou palco, do sistema e podem manifestar-se e trocar as suas diferentes perspectivas. As restantes posições permanecem temporariamente inativas, sendo empurradas para o background da identidade. O funcionamento adaptativo do sistema de prioridades assenta nessa focalização nas posições relevantes para cada momento, e na assumpção de que qualquer nova situação ou vivência pode criar as condições necessárias para recuperar e trazer a foco as posições anteriormente negligenciadas (Josephs, 2002).

Se, no entanto, esse sistema de prioridades deixa de ser flexível e coerente, determinadas posições podem ficar permanentemente reduzidas ao background, tornando-se inacessíveis e correndo o risco de serem excluídas do sistema. Essa dissociação de vozes identitárias pode resultar num afunilamento patológico da identidade (Stiles, 2002; Stiles \& Angus, 2001; Stiles, Osatuke, Glick \& Mackay, 2004). Stiles (2002) refere-se a este processo como uma incapacidade de 
assimilar vozes na identidade, vozes essas que representam recursos que são perdidos. A título de exemplo, imagine-se um paciente em que o palco é ocupado sistematicamente por vozes de passividade interpessoal, sendo as vozes mais assertivas sistematicamente relegadas ao background.

\section{Ambivalência}

A possibilidade de serem construídas inúmeras perspectivas, que dialogam e discutem a resposta mais adequada para cada situação, exige processos permanentes de tomada de decisão imbuídos de níveis diferenciados de ambivalência (Hermans \& Dimaggio, 2007). Quando o diálogo entre as diferentes posições do eu envolve uma negociação que permite chegar a uma solução co-construída, o nível de ambivalência que se mantém entre as perspectivas identitárias é funcional, porque garante a estabilidade pontual do sistema (resolução temporária) e simultaneamente a sua abertura a posteriores mudanças (possibilidade de novas resoluções).

No entanto, esse nível ideal de tensão pode evoluir para um nível demasiado elevado ou para uma situação de ausência de ambivalência. No primeiro caso, o risco é o de oscilação permanente entre duas posições discordantes ou incompatíveis que alternadamente dominam a identidade. Valsiner (2002) refere-se a este processo por "mutual in-feeding" e Gonçalves et al. (2011) estudaram o modo como esse processo está associado ao insucesso terapêutico. Essa oscilação entre duas posições da identidade fixa o sistema identitário, dificultando a emergência de alternativas (e.g. "estou deprimido" - "quero ser feliz", "mas estou deprimido", ...). No segundo caso, o risco é de apenas uma posição ter voz ativa, resultando no fechamento defensivo e monológico da identidade. Quer no primeiro caso, quer no segundo, a gestão da multivocalidade não é funcional, porque a resposta a cada nova situação é controlada e limitada a opções previamente definidas, sendo difícil a emergência de novidade.

\section{A reorganização da identidade dialógica: estratégias de intervenção terapêutica}

"Todos estes conceitos necessitam de ser interrogados.

Chegam-nos como a fruta importada: há que descascá-los, prová-los e avaliar se podem ser produtivos no chão da nossa realidade"

(Mia Couto, 2005, p. 127)

A perspectiva dialógica não se esgota enquanto grelha teórica de análise e tem-se revelado um terreno fértil para desenvolvimentos no domínio empírico e no domínio da intervenção psicoterapêutica. Comecemos por abordar algumas alterações que veio introduzir na forma de pensar e intervir na psicopatologia.

\section{Conceptualização dialógica da psicopatologia}

O bem-estar psicológico tem sido associado ao sentimento de controlo pessoal, de coerência e de integração. Portanto, o carácter multivocal da identidade, enquanto antítese a essa unidade centrada indivisível, poderia ser entendido como sinónimo de fragmentação (Hermans, 2008). A teoria da identidade dialógica defende que, apesar do risco de dispersão inerente a uma diversidade de perspectivas, o sentimento de identidade pessoal é preservado se a pessoa mantiver a capacidade e abertura para se relacionar inteiramente com todas as dimensões de si próprio e dos outros (Cooper, 2003). No entanto, certas condicionantes (sejam elas de ordem interna ou externa) podem comprometer o funcionamento adequado das estratégias de auto-organização, ameaçando o desenvolvimento adaptativo da identidade (Neimeyer, Herrero, \& Botelha, 2006).

Portanto, a principal diferença entre uma identidade funcional ou disfuncional não reside no número ou na quantidade de posições de identidade (unidade vs. multiplicidade), mas na capacidade de auto-organização das dinâmicas que estabelecem entre si (Hermans, 2008; Lysaker \& Lysaker, 2002). Consequentemente, as perturbações psicopatológicas deixam de ser entendidas como um fenómeno em si, qualitativamente distinto da "normalidade", mas como o resultado de processos disfuncionais de gestão da multiplicidade (Power, 2007).

\section{A intervenção terapêutica dialógica}

Uma intervenção terapêutica dialógica irá permitir a reformulação das narrativas identitárias, através do acesso aos diálogos que as fundamentam e atualizam. A multivocalidade parece funcionar como um extraordinário recurso terapêutico, na medida em que se torna evidente que o poder de transformação pode "estar na mão" de posições que já integram o sistema de identidade, mas que não têm voz ativa. Na sua essência, a psicoterapia é também um diálogo que poderá promover, diversificar e desafiar as conversações intra e/ou interpessoais dos pacientes (Lysaker \& Lysaker, 2004). Passamos a detalhar um conjunto de componentes que entendemos estarem presentes na reconstrução terapêutica de um sistema identitário dialógico mais funcional e adaptativo: a voz do terapeuta; a consciência da multivocalidade e a acessibilidade ao sistema identitário e a reformulação da gestão das dinâmicas entre posições.

A voz do terapeuta. A terapia pode ser vista como uma empresa dialógica entre o cliente e o terapeuta (Hermans \& Hermans-Jansen, 2004). Ao longo do processo, a relação entre os dois intervenientes torna-se desejavelmente mais sólida, o diálogo construtivo mais constante, resultando num aumento da consciência do outro. O terapeuta deixa de ser visto apenas como mais um interlocutor e passa a ser entendido como um parceiro de diálogo privilegiado. Essa proximidade permite, primeiramente, que o paciente comece a reconhecer a existência de múltiplas dimensões no outro e passe a vê-lo como uma fonte de novas ideias e compreensões. $\mathrm{O}$ desenvolvimento dessa capacidade meta-representativa (através da qual o paciente atinge uma representação de potenciais representações do terapeuta) reforça, por sua vez, a capacidade do paciente para compreender e desenvolver as suas próprias perspectivas identitárias (Semerari, Carcione, Dimaggio, Nicolò, \& Procacci, 2004).

Portanto, segundo a perspectiva dialógica a relação terapêutica envolve um cruzamento entre os sistemas identitários dos intervenientes, cada um passando a estar representado 
no sistema do outro "numa multivocalidade partilhada". A inclusão de uma posição "Eu segundo o meu Terapeuta" no sistema de significados do paciente permite disponibilizar uma perspectiva diferente, que pode funcionar como moderadora das dinâmicas internas e pode potencializar o resgate e/ou a criação de posições e relações intrapessoais (Lysaker \& Hermans, 2007). É vista como uma oportunidade de dotar o sistema identitário dos pacientes com um modelo privilegiado que permitirá reconstruir as suas visões formatadas (Power, 2007). Dado que o enriquecimento do repertório do paciente é contingente ao conteúdo e extensão do repertório do terapeuta, o próprio terapeuta deve ter um repertório extenso que lhe permita responder de múltiplas formas alternativas, não só às posições de diferentes pacientes, mas também às mudanças do repertório de um mesmo paciente durante o processo terapêutico (Dimaggio, Catania, Salvatore, Carcione, \& Nicolò, 2006; Hermans, 2006; Hermans \& Dimaggio, 2004).

A consciência da multivocalidade e a acessibilidade ao sistema identitário. Dimaggio e Stiles (2007) levantam uma questão pertinente sobre a intervenção terapêutica na identidade dialógica: como é que um terapeuta consegue criar empatia e respeitar a totalidade de um paciente que pode falar através de diferentes vozes, muitas vezes opostas (e.g. como, por exemplo, em situações de forte indecisão)? O primeiro passo consiste na facilitação da percepção e reconhecimento, por parte do paciente, do carácter multivocal da sua identidade (Smith \& Greenberg, 2007). Será importante convidá-lo a refletir sobre si a partir das múltiplas perspectivas do seu repertório (Hermans, 2006). Esse movimento continuado irá permitir que as diferentes partes da identidade acedam à consciência e se expressem (Whelton \& Greenberg, 2004).

Portanto, em vez de sintetizar as afirmações do paciente numa história coerente, o terapeuta vai procurar identificar e articular aspectos da identidade que estão camuflados, ou escondidos, no fluxo confuso de material que é trazido para a sessão, criando as condições necessárias para que todas as vozes possam ser ouvidas (Dimaggio \& Stiles, 2007; Lysaker \& Hermans, 2007; Nicolò, Carcione, Semerari, \& Dimaggio, 2007). Ao contrário dos processos tradicionais que defendem a eliminação de posições incompatíveis ou conflituosas ("problemáticas"), a intervenção dialógica assume-se como uma via de entrada e integração, no sentido da articulação dinâmica, de todas as perspectivas disponíveis. Essa diferença resulta num aumento da multiplicidade e na possibilidade de dar voz a uma maior diversidade de posições, que poderão vir a ter um papel importante na organização das dinâmicas internas do sistema identitário.

A reformulação da gestão das dinâmicas entre posições. O objetivo dessa estratégia consiste na introdução de mudanças nos padrões relacionais disfuncionais que possibilitem a promoção de encontros equilibrados entre as diversas posições. Esse processo facilita a negociação de relações assimétricas inflexíveis e a construção conjunta de interações mais adaptativas (Dimaggio \& Stiles, 2007; Georgaca, 2001; Hermans, 2001). Desse modo, o restabelecimento, a renovação e a reorganização dos diálogos internos serão canalizados através de diálogos externos terapêuticos (Dimaggio, Salvatore, Azzara, \& Catania, 2003; Lysaker
\& Lysaker, 2001; Lysaker, Lysaker, \& Lysaker, 2001). Passamos então a descrever duas estratégias de redefinição das dinâmicas intrapessoais que têm reunido o consenso de um grande número de autores e terapeutas: a promoção de coligações entre posições e o desenvolvimento de uma meta-posição.

Para reformular as relações em que, por exemplo, uma voz se torna permanentemente dominante, será necessário ativar coligações entre diferentes posições. Isoladamente as vozes submissas não conseguem fazer frente à posição que assumiu o comando e, portanto, não se conseguem fazer ouvir. A combinação das suas perspectivas poderá permitir constituir uma nova posição suficientemente forte para parar a influência generalizadora da dominante (Hermans, 2006). No entanto, habitualmente surgem dificuldades nesse processo. Seria demasiado fácil que uma voz dominante pudesse ser prontamente substituída ou empurrada para "um papel secundário" de um momento para o outro (Gonçalves \& Ribeiro, 2012). Ela vai reclamar o seu papel central e resistir à entrada de novas alternativas. Para orientar esse processo, o terapeuta terá de alternar na aliança que estabelece com as posições do paciente, de acordo com o contexto em que são mais adaptativas, tendo o cuidado de nunca ignorar ou renegar posições (Osatuke et al., 2007). Os resultados de uma coligação bem sucedida são evidentes, sendo possível reverter uma estrutura monológica estabilizada em processos dialógicos eficientes e flexíveis (Hermans, 2006).

Por outro lado, os clínicos de vários backgrounds têm prestado atenção crescente às competências meta-representativas, que são consideradas um fator essencial para a mudança. Na intervenção dialógica, vários autores referem a importância do desenvolvimento de uma meta-posição, ou Eu Observador, uma perspectiva a partir da qual a pessoa enuncia as ligações entre várias posições significativas de uma forma auto-reflexiva (Cooper, 2003; Dimaggio et al., 2003; Georgaca, 2001; Gonçalves \& Ribeiro, 2012; Hermans, 2003, 2004a; Hermans \& Hermans-Jansen, 2004; Leiman \& Stiles, 2001; Semerari et al., 2004). Essa posição alcança uma condição privilegiada para emitir avaliações mais informadas e isentas face às dinâmicas internas e para criar e moderar um espaço dialógico de comunicação e interação (Hermans, 2004a).

A aplicação prática da perspectiva dialógica parece assim incidir maioritariamente sobre a análise e reformulação do conteúdo narrativo do repertório multivocal. Partindo da premissa de que o foco da perturbação psicológica não se restringe a posições isoladas e assenta, fundamentalmente, na natureza das trocas dialógicas que estabelecem entre si, a intervenção psicoterapêutica procura priorizar a implementação de mudanças nos aspectos de auto-organização da identidade (Crossley, 2000; Hermans \& Hermans-Jansen, 2004; Hermans, Rijks, \& Kempen, 1993).

No desenvolvimento da teoria dialógica, assistimos a uma interdependência entre a dimensão prática e a dimensão empírica. As estratégias terapêuticas referidas são, simultaneamente, um resultado e um ponto de partida para novas pesquisas no campo da investigação. Desse modo, iremos descrever, de forma breve, três métodos de compreensão e reformulação da identidade dialógica. 


\section{Métodos de estudo e intervenção na identidade dialógica}

Do conjunto de procedimentos que têm sido desenvolvidos para estudar os processos dialógicos entendemos destacar o Modelo da Assimilação, o Repertório de Posições Pessoais e a Tarefa de Articulação Dialógica. Os dois primeiros por se tratarem de métodos de referência nessa perspectiva e o terceiro por se tratar da grelha de leitura por nós desenvolvida para aceder e estudar o carácter complexo e dinâmico da identidade dialógica.

O modelo da assimilação. O Modelo da Assimilação defende que as múltiplas partes da identidade, metaforicamente definidas como vozes, são traços de experiências anteriores da pessoa (Osatuke, Gray, Glick, Stiles, \& Barkham, 2004). Nesse sentido, as experiências problemáticas são também vozes que integram o sistema de identidade. No entanto, como são vozes indesejadas, sempre que emergem recebem a oposição imediata de uma ou mais vozes que representa $(\mathrm{m}) \mathrm{o}$ sistema dominante. Vão sendo progressivamente suprimidas e silenciadas, podendo no limite ser excluídas da comunidade de posições que comanda o sistema e deixar de aceder à consciência (Honos-Webb \& Stiles, 1998; Stiles et al., 2004). Portanto, o objetivo prioritário do processo terapêutico será resgatar a voz problemática e promover a sua aceitação e integração na comunidade.

Stiles e colaboradores (Honos-Webb \& Stiles, 1998; Stiles, 2002; Stiles \& Angus, 2001; Stiles et al., 2004) identificaram uma sequência de estádios ou níveis de assimilação (Escala de Assimilação das Experiências Problemáticas), que representam a progressiva integração da voz problemática no sistema de identidade. Os autores defendem a existência de oito níveis de assimilação terapêutica: 0 - dissociada (a voz problemática não tem expressão e os pacientes não estão conscientes dessa voz ou problema); 1 - pensamentos indesejados/evitamento ativo (a voz problemática começa a aceder à consciência através das intervenções do terapeuta, sendo imediatamente evitada ou suprimida pela representante da comunidade dominante); 2 - vaga consciência/ emergência (a voz problemática emerge à consciência de forma sustentada e corrompe a prévia unidade ilusória da identidade, os pacientes estão conscientes dessa voz, mas não a conseguem formular de forma clara); 3 - afirmação do problema/clarificação (os pacientes reconhecem explicitamente a voz problemática, distinguindo-a da dominante e as duas vozes alcançam um peso igual e conseguem dialogar); 4 - compreensão/insight (a voz problemática é formulada e compreendida e estabelece com a dominante um entendimento empático, uma ponte de significado); 5 - aplicação (o mútuo entendimento alcançado é utilizado para as vozes trabalharem em conjunto sobre as questões que se colocam à comunidade); 6 - recurso/resolução de problemas (a voz problemática torna-se um recurso para resolver problemas e todo o repertório de vozes passa a poder ser utilizado de forma flexível) e 7 - integração/mestria (os pacientes são capazes de gerar soluções automaticamente, as vozes são completamente integradas na comunidade servindo de recurso para novas situações).

$O$ repertório de posições pessoais. O Repertório de Posições Pessoais (RPP), desenvolvido por Hermans (2001), é um instrumento com grande relevância no contexto clínico dialógico, porque permite aceder e introduzir mudanças no conteúdo e na organização do sistema pessoal de significado. $\mathrm{O}$ autor salienta três princípios organizadores do seu método: 1) construção de um sistema de posições recheado de oposições, contrastes, conflitos e fragmentos narrativos; 2) potencialização da descentração da identidade e 3) estabelecimento de relações dialógicas entre as posições. Esse procedimento metodológico é desenvolvido ao longo das sessões terapêuticas, num trabalho colaborativo de coconstrução entre o terapeuta e o paciente.

No primeiro momento, os pacientes identificam, com o auxílio de listas já definidas, mas respeitando um espaço para a personalização, o seu conjunto pessoal de posições de identidade internas e externas. As posições internas são conceptualizadas como auto-reflexivas e autoavaliativas e são investigadas como sendo situacionalmente específicas (por exemplo, Eu como Compreensiva, Eu como Vulnerável, Eu como Mulher, Eu como Mãe). As posições externas correspondem às vozes de outros significativos que povoam de forma ativa a identidade dos pacientes (por exemplo, $O$ meu Marido, A minha Irmã, O meu Amigo). A partir desse sistema de posições é elaborada uma matriz de dupla entrada (posições internas x posições externas), na qual é cotado o grau de proeminência de cada posição interna para as posições externas. Essa oportunidade de aceder à audiência de cada posição identitária permite um primeiro estudo da relação entre vozes. No entanto, trata-se de uma avaliação quantitativa que não disponibiliza uma indicação clara das dimensões qualitativas das dinâmicas intrapessoais.

Nesse sentido, é solicitado aos pacientes que mantenham um diário das experiências diárias relevantes e das posições envolvidas (Hermans, 2001). Essa estratégia pretende aumentar a percepção dos pacientes sobre o tipo de relações disfuncionais que podem ocorrer entre as posições do repertório. Estando conscientes da presença desse tipo de dinâmicas, os pacientes terão de perspectivar e testar formas de encontro mais adaptativas entre as posições do eu. As mudanças alcançadas devem ser transformadas em partes adquiridas e estabelecidas do repertório, sendo praticadas até que se tornem novos hábitos (Hermans \& Hermans-Jansen, 2004).

A tarefa de articulação dialógica. Partindo do trabalho desses autores, e estando conscientes da necessidade de um investimento empírico e prático em metodologias inovadoras que captem os processos dialógicos que ocorrem na identidade, desenvolvemos um procedimento empírico de acesso ao repertório identitário (para mais detalhes ver em Rosa, Duarte, \& Gonçalves, 2008; Rosa \& Gonçalves, 2008). A Tarefa de Articulação Dialógica (TAD) é uma entrevista semi-estruturada que convida o participante a identificar a multivocalidade da sua identidade e a narrar os diálogos que as diferentes vozes estabelecem.

Primeiramente, é pedido ao participante que identifique as dimensões mais significativas da sua identidade, as quais geralmente correspondem a papéis sociais, características pessoais, atividades (por exemplo, Eu Filha, Eu Conjugal, Eu Pessimista, Eu Desportista). O repertório de posições de identidade que é definido reflete apenas o conjunto de posições que, naquele momento "aqui e agora", ocupa o 
"palco das operações" do sistema. As restantes posições permanecem em background, porque não foram ativadas pelo contexto presente. Em seguida, pedimos ao participante para imaginar que os diferentes elementos da sua identidade têm uma voz independente e para fazer o exercício de se mover entre essas posições e narrar as dinâmicas mais recorrentes entre elas. $\mathrm{Na}$ exploração dessas relações entre posições, o investigador procura clarificar algumas questões: a presença de diálogos e/ou monólogos; o acordo/desacordo entre perspectivas; a assimetria/simetria entre posições e o nível de conflito envolvido.

A aplicação desse procedimento num estudo empírico (ver Rosa \& Gonçalves, 2010) permitiu identificar seis padrões recorrentes nas dinâmicas intrapessoais.

Padrão de alienação monológica. Neste padrão, uma única posição vive a ilusão de que é o habitante isolado da identidade. Essa posição não está disponível para se relacionar ou ouvir as restantes, porque nega a sua existência. Representa um momento de negação da multivocalidade, de impedimento à entrada de inovação e, portanto, de estagnação monológica. Exemplo: "O Eu Filha e o Eu Conjugal é que nunca se encontram mesmo. Não se conhecem, não têm referências um do outro, não sabem por onde é que anda um e o outro, são perfeitos desconhecidos."

Padrão de exclusividade intencional. Tal como no anterior, assistimos ao monólogo de uma posição. Mas, neste caso, a posição decide, de forma consciente, negligenciar ou evitar as restantes, porque considera ser a opção mais adaptativa para o sistema naquele momento. Trata-se de um constrangimento funcional, porque é pontual e geralmente serve de preliminar para uma dinâmica mais dialógica. Exemplo: "O Eu como Mãe não estava activo e foi posto de parte. Portanto, foi um momento do Eu Conjugal. Foi só o Eu Conjugal, porque ele precisava de tempo só para si, precisa de momentos como este para se restabelecer $e$ ganhar forças."

Padrão de autoritarismo. Este padrão vem introduzir o diálogo entre as posições de identidade. No entanto, o encontro resulta na ativação de uma hierarquia rígida, marcada pelo domínio invariável de uma posição, independentemente das variações no contexto. Assim, apesar de se manifestarem, as perspectivas das posições subjugadas não contribuem para o resultado final e todo o sistema estará em risco se ocorrer uma mudança contextual que não adquira significado nos parâmetros da perspectiva dominante. Exemplo: "Estou a atravessar uma fase mais do Eu Profissional, o Eu Conjugal queixa-se e com razão. Estamos a trabalhar num projecto importante e portanto o Eu Profissional tem mesmo de estar no topo das prioridades e ponto final. Mas em termos de futuro, para as coisas correrem bem, eu gostava de os conseguir equilibrar."

Padrão de liderança. Tal como no padrão anterior, as posições também dialogam e também se ativa uma dinâmica assimétrica. No entanto, neste caso, instala-se uma hierarquia flexível, que representa uma igualdade de oportunidades qualquer posição do sistema (a mais adaptativa para a situação) poderá sobrepor-se e liderar as restantes. Exemplo: " $O$ Eu Conjugal tomou uma dimensão maior e mais abrangente do que o Eu Sociável, porque era algo que fazia sentido e que ambos queriam."
Padrão de multivocalidade monocórdica. Ao contrário dos dois padrões anteriores, que são marcados pela assimetria, neste padrão o diálogo entre as posições caracteriza-se por uma troca simétrica. No entanto, esse equilíbrio relacional não representa um momento de coconstrução e de entrada de inovação, porque as perspectivas se mantêm semelhantes e concordantes. Essa dinâmica parece corresponder a uma estratégia das posições para garantir um momento de estabilidade do sistema. Exemplo: "Eu acho que o que gerou mais desconforto foi a semelhança entre as opiniões do Eu Filha e do Eu Conjugal. Esta concordância causou tensão entre eles, porque não estão habituados a andar a par e passo $e$ a estar de acordo."

Padrão de complementaridade dialógica. É neste padrão que a natureza dialógica da comunicação entre as posições de identidade atinge o seu expoente máximo. A disponibilidade para um encontro simétrico e de total entrega ao diálogo (sem receio da mudança) resulta na coautoria de novos significados. Exemplo: "Eu estou a tentar repensar o Eu Mãe e o Eu Conjugal. Portanto, estou a tentar no Eu Mãe ser mais atenta e mais calma. E no Eu Conjugal quero conseguir ter um papel também mais dedicado, mais presente. Por outro lado, eu penso que o Eu Mãe tem ajudado a conhecer melhor o Eu Conjugal, há sempre pensamentos e acções que nunca tinha tido ou que não conhecia. É importante estarem juntos, mas têm de saber o seu lugar. Têm que estar muito bem definidos e ter limites claros."

A definição dessa tipologia não deve ser entendida como uma forma de delimitação e generalização estática das dinâmicas intrapessoais. Será importante destacar que a sequência em que os padrões surgem ou a predominância de um determinado padrão são elementos altamente personalizados e idiossincráticos.

\section{Conclusão}

A perspectiva de que a capacidade de auto-organização da identidade dialógica é um elemento fundamental para o bem-estar psicológico, e de que a mesma pode ser reformulada através da intervenção terapêutica serviram de mote à revisão teórica apresentada. Os diferentes contributos reunidos reforçam a ideia de que a identidade se encontra em permanente construção, resultando de um processo contínuo de organização e reorganização das dinâmicas entre as diferentes posições do eu.

Cada momento experiencial representa, simultaneamente, uma oportunidade de mudança e um risco de disfunção das estratégias subjacentes ao sistema de gestão interna da identidade. A manutenção de um sentido integrado de continuidade e diversidade pessoal, bem como a sua permanente atualização, resultam da combinação entre um nível moderado de ambivalência nas dinâmicas intrapessoais e uma atividade flexível dos sistemas hierárquico e das prioridades que as regulam. No entanto, qualquer alteração no contexto pode comprometer esse equilíbrio e os indivíduos são confrontados com a difícil tarefa de reaprender a organizar a multivocalidade.

O processo terapêutico pode então ser visto como uma oportunidade de reconstrução de um espaço dialógico, que 
permite tornar audíveis todas as vozes identitárias relevantes, restabelecer um canal de comunicação produtivo entre elas e reorganizar de forma adaptativa as suas dinâmicas. A intervenção terapêutica dialógica possibilitará o estabelecimento de conexões relacionais que facilitam a introdução de novas tonalidades e matizes na compreensão e vivência da identidade dialógica.

O conjunto de padrões de organização das dinâmicas intrapessoais apresentado corresponde a uma possível grelha de leitura do processo de construção da identidade dialógica. A exploração de combinações entre elementos de diferentes padrões em construções híbridas, a descoberta de novos padrões ou, inclusivamente, a possibilidade de identificar perfis específicos de organização que subjazem a problemas psicopatológicos afiguram-se como interessantes linhas de investigação futura. Será, portanto, importante continuar a desenvolver métodos de investigação e estratégias terapêuticas que permitam aceder, compreender e promover a re-autoria das dinâmicas processuais que ocorrem no sistema de identidade.

\section{Referências}

Cooper, M. (2003). "I-I" and "I-ME": Transposing Buber's interpersonal attitudes to the intrapersonal plane. Journal of Constructivist Psychology, 16(2), 131-153.

Couto, M. (2005). Pensatempos. Textos de opinião. Lisboa, Portugal: Editorial Caminho.

Crossley, M. (2000). Narrative psychology, trauma and the study of self/identity. Theory \& Psychology, 10(4), 527-546.

Dimaggio, G., Catania, D., Salvatore, G., Carcione, A., \& Nicolò, G. (2006). Psychotherapy of paranoid personality disorder from the perspective of dialogical self theory. Counselling Psychology Quarterly, 19(1), 69-87.

Dimaggio, G., Salvatore, G., Azzara, C., \& Catania, D. (2003). Rewriting self-narratives: The therapeutic process. Journal of Constructivist Psychology, 16(2), 155-181.

Dimaggio, G., \& Stiles, W. (2007). Psychotherapy in light of internal multiplicity. Journal of Clinical Psychology, 63(2), 119-127.

Georgaca, E. (2001). Voices of the self in psychotherapy: A qualitative analysis. British Journal of Medical Psychology, 74(2), 223-236.

Gonçalves, M. M., Matos, M., \& Santos, A. (2009). Narrative therapies and the nature of "unique outcomes" in the construction of change. Journal of Constructivist Psychology, 22, 1 - 23.

Gonçalves, M. M., \& Ribeiro, A. (2012). Narrative processes of innovation and stability within the dialogical self. In $\mathrm{H}$. Hermans, \& T. Gieser (Eds.), Handbook of dialogical self theory (pp. 310-318). Cambridge, UK: Cambridge University Press.

Gonçalves, M. M., Ribeiro, A. P., Conde, T., Matos, M., Santos, A., Martins, C., \& Stiles, W. B. (2011). The role of mutual infeeding in maintaining problematic self-narratives: Exploring one path to therapeutic failure. Psychotherapy Research, 21, 27-40.

Guilfoyle, M. (2006). Using power to question the dialogical self and its therapeutic application. Counselling Psychology Quarterly, 19(1), 89-104.
Hermans, H. (1996). Voicing the self: From information processing to dialogical interchange. Psychological Bulletin, 119(1), 31-50.

Hermans, H. (2001). The construction of a personal position repertoire: Method and practice. Culture \& Psychology, 7(3), 323-365.

Hermans, H. (2002). The dialogical self as a society of mind. Theory \& Psychology, 12(2), 147-160.

Hermans, H. (2003). The construction and reconstruction of a dialogical self. Journal of Constructivist Psychology, 16(2), 89-130.

Hermans, H. (2004a). The dialogical self: Between exchange and power. In H. Hermans \& G. Dimaggio (Eds.), The dialogical self in psychotherapy (pp. 13-28). New York: BrunnerRoutledge.

Hermans, H. (2004b). Introduction: The dialogical self in a global and digital age. Identity: An International Journal of Theory and Research, 4(4), 297-320.

Hermans, H. (2006). The self as a theatre of voices: Disorganization and reorganization of a position repertoire. Journal of Constructivist Psychology, 19(2), 147-169.

Hermans, H. (2008). How to perform research on the basis of dialogical self theory? Introduction to the special issue. Journal of Constructivist Psychology, 21(3), 185-199.

Hermans, H., \& Dimaggio, G. (2004). The dialogical self in psychotherapy: Introduction. In H. Hermans \& G. Dimaggio (Eds.), The dialogical self in psychotherapy (pp. 1-10). New York: Brunner-Routledge.

Hermans, H., \& Dimaggio, G. (2007). Self, identity, and globalization in times of uncertainty: A dialogical analysis. Review of General Psychology, 11(1), 31-61.

Hermans, H., \& Hermans-Jansen, E. (2004). The dialogical construction of coalitions in a personal position repertoire. In H. Hermans, \& G. Dimaggio (Eds.), The dialogical self in psychotherapy (pp. 124-137). New York: BrunnerRoutledge.

Hermans, H., \& Kempen, H. (1993). The dialogical self: Meaning as movement. San Diego: Academic Press.

Hermans, H., Rijks, T., \& Kempen, H. (1993). Imaginal dialogues in the self: Theory \& method. Journal of Personality, 61(2), 207-236.

Honos-Webb, L., \& Stiles, W. (1998). Reformulation of assimilation analysis in terms of voices. Psychotherapy, 35(1), 23-33.

Josephs, I. (2002). The hopi in me: The construction of a voice in the dialogical self from a cultural psychological perspective. Theory \& Psychology, 12(2), 161-173.

Leiman, M., \& Stiles, W. (2001). Dialogical sequence analysis and the zone of proximal development as conceptual enhancements to the assimilation model: The case of Jan revisited. Psychotherapy Research, 11(3), 311-330.

Lysaker, P. (2006). Psychotherapy and schizophrenia: An analysis of requirements of an individual psychotherapy for persons with profoundly disorganized selves. Journal of Constructivist Psychology, 19(2), 171-189.

Lysaker, P., \& Hermans, H. (2007). The dialogical self in psychotherapy for persons with schizophrenia: A case study. Journal of Clinical Psychology, 63(2), 129-139.

Lysaker, P., \& Lysaker, J. (2001). Psychosis and the disintegration of dialogical self-structure: Problems posed by schizophrenia for the maintenance of dialogue. British Journal of Medical Psychology, 74(1), 23-33. 
Lysaker, P., \& Lysaker, J. (2002). Narrative structure in psychosis: Schizophrenia and disruptions in the dialogical self. Theory \& Psychology, 12,(2), 207-220.

Lysaker, P., \& Lysaker, J. (2004). Dialogical transformation in the psychotherapy of schizophrenia. In H. Hermans \& G. Dimaggio (Eds.), The dialogical self in psychotherapy (pp. 205-219). New York: Brunner-Routledge.

Lysaker, P., Lysaker, J., \& Lysaker, J. (2001). Schizophrenia and the collapse of the dialogical self: Recovery, narrative and psychotherapy. Psychotherapy: Theory, Research, Practice, Training, 38(3), 252-261.

McAdams, D. P. (2001). The person: An integrated introduction to personality psychology (3rd ed.). Fort Worth, TX: Harcourt College Publishers.

Neimeyer, R., Herrero, O., \& Botelha, L. (2006). Chaos to coherence: Psychotherapeutic integration of traumatic loss. Journal of Constructivist Psychology, 19(2), 127-145.

Nicolò, G., Carcione, A., Semerari, A., \& Dimaggio, G. (2007). Reaching the covert, fragile side of patients: The case of narcissistic personality disorder. Journal of Clinical Psychology, 63(2), 141-152.

Osatuke, K., Gray, M., Glick, M., Stiles, W., \& Barkham, M. (2004). Hearing voices: Methodological issues in measuring internal multiplicity. In H. Hermans, \& G. Dimaggio (Eds.), The dialogical self in psychotherapy (pp. 237-254). New York: Brunner-Routledge.

Osatuke, K., Mosher, J., Goldsmith, J., Stiles, W., Shapiro, D., Hardy, G., \& Barkham, M. (2007). Submissive voices dominate in depression: Assimilation analysis of a helpful session. Journal of Clinical Psychology, 63(2), 153-164.

Power, M. (2007). The multistory self: Why the self is more than the sum of its autoparts. Journal of Clinical Psychology, 63(2), 187-198.

Rosa, C., Duarte, F., \& Gonçalves, M. M. (2008). Self and dialogical articulation of multivocality: Proposal of an analysis model. In S. Salvatore, J. Valsiner, S. Strout, \& J. Clegg (Eds.), YIS: Yearbook of Idiographic Science 2008 - Volume 1 (pp.1-23). Roma: Firera Publishing Group.

Rosa, C., \& Gonçalves, M. M. (2008). Dialogical self and close relationships: Looking for ambivalences. Studia Psychologica, 8, 89-108.

Rosa, C., \& Gonçalves, M. M. (2010). Um olhar empírico sobre a identidade dialógica: Um estudo sobre a conjugalidade. Psychologica, 53, 81-108.

Salgado, J., \& Gonçalves, M. M. (2007). The dialogical self: Social, personal and (un)conscious. In A. Rosa, \& J. Valsiner (Eds.), The Cambridge handbook of socio-cultural psychology (pp. 608-621). Cambridge, UK: Cambridge University Press.
Sarbin, T. R. (1986). The narrative as root metaphor for psychology. In T. R. Sarbin (Ed.), Narrative psychology: The storied nature of human conduct (pp. 3-21). New York: Praeger.

Sarbin, T. R. (1993). The narrative as the root metaphor for contextualism. In S. Hayes, L. Hayes, H. Reese, \& T. R. Sarbin (Eds.), Varieties of scientific contextualism (pp. 51-65). Reno, NV: Context Press.

Semerari, A., Carcione, A., Dimaggio, G., Nicolò, G., \& Procacci, M. (2004). A dialogical approach to patients with personality disorders. In H. Hermans, \& G. Dimaggio (Eds.), The dialogical self in psychotherapy (pp. 220-234). New York: Brunner-Routledge.

Smith, K., \& Greenberg, L. (2007). Internal multiplicity in emotionfocused psychotherapy. Journal of Clinical Psychology, 63( 2), 175-186.

Stiles, W. (2002). Assimilation of problematic experiences. In J. Norcross (Ed.), Psychotherapy relationships that work: Therapist contributions and responsiveness to patients (pp. 357-365). New York: Oxford University Press.

Stiles, W., \& Angus, L. (2001). Qualitative research on clients' assimilation of problematic experiences in psychotherapy. In J. Frommer, \& D. Rennie (Eds.) Qualitative psychotherapy research: Methods and methodology (pp. 111-126). Lengerich, Germany: Past Science Publishers.

Stiles, W., Osatuke, K., Glick, M., \& Mackay, H. (2004). Encounters between internal voices generate emotion: An elaboration of the assimilation model. In H. Hermans, \& G. Dimaggio (Eds.), The dialogical self in psychotherapy (pp. 91-107). New York: Brunner-Routledge.

Valsiner, J. (2002). Forms of dialogical relations and semiotic autoregulation within the self. Theory \& Psychology, 12(2), 251-265.

Valsiner, J. (2007). Culture in minds and societies: Foundations of cultural psychology. Worcester, New Delhi.

Whelton, W., \& Greenberg, L. (2004). From discord to dialogue: Internal voices and the reorganization of the self in processexperiential therapy. In H. Hermans, \& G. Dimaggio (Eds.), The dialogical self in psychotherapy (pp. 108-123). New York: Brunner-Routledge. 